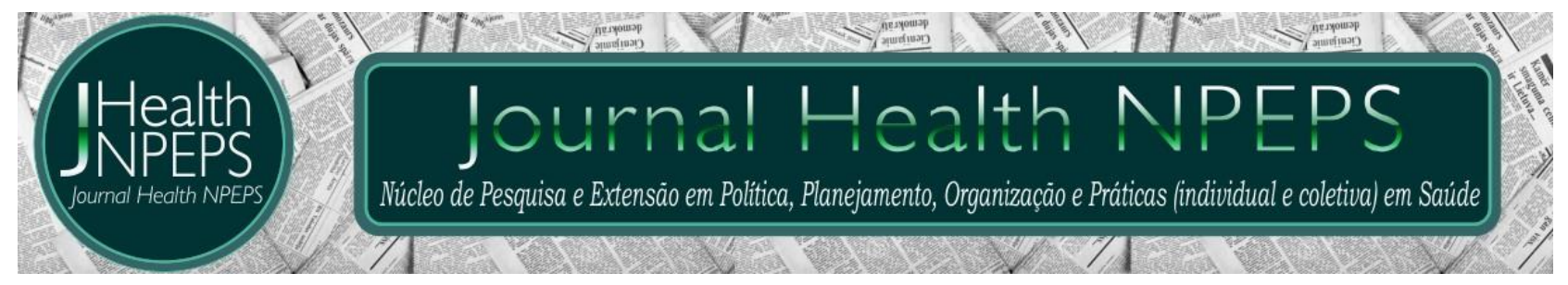

http://dx.doi.org/10.30681/252610103106

ARTIGO ORIGINAL

\title{
Reprocessamento de materiais utilizados em salões de beleza e biossegurança dos profissionais envolvidos
}

\section{Reprocessing of materials used in beauty salons and biosafety of professionals involved}

\section{Reprocesamiento de materiales utilizados en salones de belleza y bioseguridad de los profesionales envolvidos}

\author{
Vanessa Bordin ${ }^{1}$, Débora Cristina Ignácio Alves ${ }^{2}$, Letícia Katiane Martins ${ }^{3}$, Mateus \\ Souza da Luz ${ }^{4}$, Fabiana Gonçalves de Oliveira Azevedo Matos ${ }^{5}$
}

\section{RESUMO}

Objetivo: verificar como ocorrem os processos de limpeza, desinfecção e esterilização dos materiais utilizados nos salões de beleza, bem como o processo de trabalho desenvolvido, conforme Resolução da Secretaria de Saúde do Estado do Paraná $n^{\circ}$ 700/2013. Método: estudo exploratório, descritivo e quantitativo. A pesquisa foi desenvolvida com manicures/pedicures de salões de beleza em Cascavel- Paraná, através de um instrumento semiestruturado, no período de abril a junho de 2016. Todas as análises estatísticas foram realizadas no programa XLStat2015, utilizando o $p$-valor com nível de significância de 0,05. Resultados: a maioria dos entrevistados utiliza a estufa como método de esterilização. Os principais materiais e instrumentais esterilizados foram as espátulas de inox, alicates e os palitos de inox. Após o procedimento de esterilização, nenhum dos salões de beleza pesquisados utilizam método de controle deste processo, ou seja, integradores químicos e indicadores biológicos. Conclusão: quanto ao método de esterilização, $86,0 \%$ dos entrevistados não seguem a Resolução Estadual e, 64,9\% utilizam parâmetros de tempo de exposição dos materiais e temperatura do equipamento diferentes daquelas preconizadas pelos órgãos fiscalizadores e legislações vigentes.

\footnotetext{
${ }^{1}$ Enfermeira. Pós-graduanda. Universidade Estadual do Oeste do Paraná (UNIOESTE). Cascavel, Paraná, Brasil. E-mail: vanessa.bordin@hotmail.com ORCID ID: https://orcid.org/0000-0003-2870-0079 Autor principal - Endereço para correspondência: Rua Aimorés, no 187, apto no 04, Bairro Santo Onofre, Cascavel, Paraná, Brasil. CEP: 85806330.

${ }^{2}$ Enfermeira. Doutora. Universidade Estadual do Oeste do Paraná (UNIOESTE). Cascavel, Paraná, Brasil. E-mail: dcialves@gmail.com ORCID ID: https://orcid.org/0000-0001-6892-366X

${ }^{3}$ Enfermeira. Pós-graduanda. Universidade Estadual do Oeste do Paraná (UNIOESTE). Cascavel, Paraná, Brasil. E-mail: leticiakmartins@gmail.com ORCID ID: https://orcid.org/0000-0003-2650-9721

${ }^{4}$ Enfermeiro. Pós-graduando. Universidade Estadual do Oeste do Paraná (UNIOESTE). Cascavel, Paraná, Brasil. E-mail: matthheus72@gmail.com ORCID ID: https://orcid.org/0000-0003-2405-0152

${ }^{5}$ Enfermeira. Doutora. Universidade Estadual do Oeste do Paraná (UNIOESTE). Cascavel, Paraná, Brasil. E-mail: fabianamatos@hotmail.com ORCID ID: https://orcid.org/0000-0002-5283-5363
}

Este artigo está licenciado sob forma de uma licença Creative Commons Atribuição 4.0 Internacional, que permite uso irrestrito, distribuição e reprodução em qualquer meio, desde que a publicação original seja corretamente citada. 
Descritores: Contenção de Riscos Biológicos; Esterilização; Centros de Embelezamento e Estética.

\begin{abstract}
Objective: to check how the processes of cleaning, disinfecting and sterilizing the materials used in beauty salons occur, as well as the work process developed, according to Resolution of the Health Department of the State of Paraná No. 700/2013. Method: exploratory, descriptive and quantitative study. The research was developed with manicures / pedicures of beauty salons in Cascavel- Paraná, through a semistructured instrument, from April to June 2016. All the statistical analyzes were performed in the program XLStat2015, using the $p$-value with level of significance of 0.05. Results: most of the interviewees use the greenhouse as a sterilization method. The main sterilized materials and instruments were stainless steel spatulas, pliers and stainless steel sticks. After the sterilization procedure, none of the beauty salons researched uses this method of controlling this process, that is, chemical integrators and biological indicators. Conclusion: Regarding the sterilization method, $86.0 \%$ of respondents do not follow the State Resolution, and $64.9 \%$ use time parameters of material exposure and equipment temperature different from those recommended by the regulatory agencies and current legislations.
\end{abstract}

Descriptors: Containment of Biohazards; Sterilization; Beauty and Aesthetics Centers.

\title{
RESUMEN
}

Objetivo: verificar como ocurre los procesos de limpieza, desinfección y esterilización de los materiales utilizados en los salones de belleza, así como el proceso de trabajo desarrollado, conforme a la Resolución de la Secretaría de Salud del Estado de Paraná $n^{\circ}$ 700/2013. Método: estudio exploratorio, descriptivo y cuantitativo. La investigación fue desarrollada con manicuras / pedicures de salones de belleza en Cascavel - Paraná, a través de un instrumento semiestructurado, en el período de abril a junio de 2016. Todos los análisis estadísticos se realizaron en el programa XLStat2015, utilizando el pvalor con nivel de calidad significancia de 0,05. Resultados: la mayoría de los entrevistados utilizan el invernadero como método de esterilización. Los principales materiales e instrumentales esterilizados fueron las espátulas de inox, alicates y los palillos de acero inoxidable. Después del procedimiento de esterilización, ninguno de los salones de belleza encuestados utilizan método de control de este proceso, es decir, integradores químicos e indicadores biológicos. Conclusión: en cuanto al método de esterilización, el 86,0\% de los entrevistados no siguen la Resolución Estadual y el 64,9\% utilizan parámetros de tiempo de exposición de los materiales y temperatura del equipo diferentes de aquellos preconizados por los organismos fiscalizadores $y$ legislaciones vigentes.

Descriptores: Contención de Riesgos Biológicos; Esterilización; Centros de Belleza y Estética.

\section{INTRODUÇÃO}

O desenvolvimento econômico do país e os meios de comunicação têm influenciado o aumento da renda e trazendo consigo padrões de imagem e beleza, atingindo todas as camadas sociais, faixas etárias e ambos os sexos. Tal condição tem 
inspirado os indivíduos a se preocuparem com a qualidade de vida, sobretudo, quanto aos cuidados com o corpo, sendo, necessário o crescimento quantitativo de profissionais que possam atender esta demanda, incluindo as manicures e pedicures ${ }^{1}$.

Entretanto, esse crescimento não tem acompanhado a devida qualificação profissional, expondo trabalhadores e clientela atendida, aos riscos inerentes às atividades desenvolvidas².

Os principais riscos ocupacionais a que os profissionais da beleza que realizam estas atividades estão submetidos, incluem principalmente as doenças infectocontagiosas. Desta forma, as manicures e pedicures manipulam tecidos nas mãos e pés, especialmente pela prática habitual no Brasil de remover o eponíquio (cutícula) ${ }^{3}$, sendo assim, estas, acabam por se exporem a estes riscos de exposições.

No cuidado das unhas é comum ocorrerem acidentes com materiais perfuro cortantes, podendo levar a transmissão de patógenos de relevância epidemiológica e de impacto significativo na saúde pública, tais como o vírus da hepatite $B(\mathrm{VHB})$, hepatite $C$ (VHC) e o vírus da imunodeficiência humana (HIV), além de micoses, dermatites e furunculoses ${ }^{4-8}$.

Além disso, os materiais e instrumentos utilizados podem se tornar veículos de agentes infecciosos se não forem descartados ou reprocessados adequadamente após cada uso $0^{9,10}$.

Desta forma, serviços de embelezamento que não observam as normas de biossegurança e não adotam processos de desinfecção e esterilização dos materiais, podem transmitir doenças infecciosas e, ainda, provocar lesões dermatológicas ${ }^{4}$. Isso posto, o processo de esterilização é indispensável, tendo como objetivo primordial a destruição completa de todos os micro-organismos vivos, incluindo esporos e vírus ${ }^{1}$, tendo que ser realizado por equipamentos ${ }^{11,12}$.

Sendo assim, com a publicação da Resolução da Diretoria Colegiada (RDC) $n^{\circ} 15$ de 2012, esta proporcionou mudanças significativas no que diz respeito aos requisitos de boas práticas para o funcionamento dos serviços que realizam o processamento de produtos para a saúde, visando à segurança do paciente e dos profissionais envolvidos, não sendo permitida a utilização de estufas para a esterilização de produtos para saúde ${ }^{13}$, as quais estas, devem ser seguidas obrigatoriamente. 
Partindo-se desse pressuposto, a questão norteadora dessa pesquisa se deu através da seguinte indagação: Os salões de beleza processam adequadamente os materiais após serem utilizados?

A partir disso, o objetivo do estudo foi verificar como ocorre os processos de limpeza, desinfecção e esterilização dos materiais utilizados nos salões de beleza, bem como o processo de trabalho desenvolvido, conforme Resolução da Secretaria de Saúde do Estado do Paraná n $700 / 2013^{14}$.

\section{MÉTODO}

O estudo é do tipo descritivo, exploratório e quantitativo. Foi desenvolvido no período de abril a junho do ano de 2016, em salões de beleza do município de Cascavel$P R$, especificamente na região sul do município, que conta com cinco bairros afins. A população foi composta por manicures/pedicures que atuam nestes estabelecimentos.

Os critérios de inclusão foram: estabelecimento de beleza com pelo menos um (a) profissional manicure/pedicure, maior de 18 anos e que voluntariamente consentiram em participar da pesquisa, após assinarem o Termo de Consentimento Livre e Esclarecido (TCLE).

Foram excluídos da amostra, os estabelecimentos de beleza que foram visitados mais de três vezes e estavam fechados e estabelecimentos que atuassem apenas no ramo de cabelo/barba. Assim, a amostra da pesquisa correspondeu a 61 estabelecimentos de beleza que aceitaram participar efetivamente da presente pesquisa.

Para a coleta de dados foi elaborado um instrumento semiestruturado contendo perguntas abertas e fechadas, contendo dados de caracterização do estabelecimento; dados de caracterização do entrevistado; dados de caracterização do processo de trabalho e dados de conhecimento específico. A realização do teste-piloto para testagem do instrumento ocorreu em um salão de beleza (não incluso na amostra) e as respostas foram analisadas para verificar a congruência das questões, de acordo com o objetivo da pesquisa.

Os profissionais dos salões de beleza foram contatados mediante visita ao estabelecimento, sendo realizada a apresentação do pesquisador e a esclarecimentos sobre a pesquisa. E, mediante aceite, a coleta era realizada, com duração média de 30 
minutos.

Os dados foram devidamente tabulados em planilha do software Microsoft Office Excel $(\AA$, versão 2013 , e posteriormente sintetizados por meio de estatística descritiva, por meio de frequências absoluta e relativa. As frequências das categorias de resposta foram comparadas entre si por meio do teste de qui quadrado para aderência ou $k$ proporções, seguido do teste de acompanhamento de Marascuilo. Todas as análises estatísticas foram realizadas no programa XLStat2015, utilizando o $p$-valor com nível de significância de 0,05.

Todos os aspectos éticos previstos na Resolução $n^{\circ} 466$ de 12 de dezembro de 2012, do Conselho Nacional de Saúde/MS, que trata de diretrizes e normas regulamentadoras com pesquisas que envolvem seres humanos foram respeitados. A pesquisa foi aprovada pelo Comitê de Ética em Pesquisa (CEP) da Universidade Estadual do Oeste do Paraná (UNIOESTE), conforme parecer favorável número 1.447.806/2016.

\section{RESULTADOS}

Quanto aos processos de reprocessamento dos materiais, foi possível observar que os entrevistados fazem uso principalmente de álcool líquido em 38 (62,3\%) estabelecimentos de salões de beleza e água/sabão comum em 23 (37,7\%). Destes, a maioria mantém os materiais e instrumentais em imersão durante 3 minutos para a descontaminação 45 (73,8\%). Os principais materiais e instrumentais citados pelos entrevistados foram espátula de inox 61 (100\%), alicates $60(98,4 \%)$ e palito de inox 44 (72,1\%) (Tabela 1).

No presente estudo, a maioria dos entrevistados faz uso de métodos de esterilização em 57 (93,4\%) estabelecimentos, sendo utilizada a estufa em 49 (86,0\%) salões de beleza. Os principais materiais e instrumentais citados que passam por processo de esterilização são: espátulas de inox 57 (100,0\%), alicates, 57 (100,0\%) e os palitos de inox, 44 (77,2\%) (Tabela 2).

As temperaturas e os tempos de exposição dos materiais não foram uniformes, sendo que a maior parte dos entrevistados 38 (64,9\%) informou tempos e temperaturas diferentes das preconizadas, sendo estas mencionadas como "outros" (Tabela 2).

Em relação aos processos de desinfecção ou esterilização dos materiais, 57 $(93,4 \%)$ dos entrevistados realizavam, sendo que $32(56,1 \%)$ realizam ao final do 
expediente e $17(29,8 \%)$ entre os atendimentos. A maioria faz uso de embalagem para o processo de esterilização 43 (75,4\%), em especial, o papel alumínio 36 (83,7\%) (Tabela 3).

Tabela 1 - Frequências das categorias de variáveis relacionadas ao processo de trabalho. Abril a junho de 2016. Cascavel-PR, Brasil.

\begin{tabular}{|c|c|c|c|c|}
\hline \multirow{3}{*}{$\begin{array}{l}\quad \text { Variável } \\
\text { Método para limpeza/ } \\
\text { descontaminação de } \\
\text { materiais }\end{array}$} & Categorias & $n$ & $\%$ & \multirow{3}{*}{$\begin{array}{c}\text { p-valor } \\
-\end{array}$} \\
\hline & Sim & 61 & 100 & \\
\hline & Não & 0 & 0 & \\
\hline \multirow{9}{*}{ Produto utilizado } & Água e sabão comum & 23 & 37,7 & \multirow{9}{*}{$<0,0001$} \\
\hline & Detergente comum & 4 & 6,6 & \\
\hline & Álcool líquido & 38 & 62,3 & \\
\hline & Álcool gel & 5 & 8,2 & \\
\hline & Detergente enzimático & 4 & 6,6 & \\
\hline & Soluções a base de cloro & 0 & 0,0 & \\
\hline & Ácido peracético & 1 & 1,6 & \\
\hline & Outros: Shampoo & 2 & 3,3 & \\
\hline & Sabonete neutro & 1 & 1,6 & \\
\hline \multirow{6}{*}{$\begin{array}{l}\text { Tempo de exposição dos } \\
\text { materiais e instrumentais ao } \\
\text { método de limpeza/ } \\
\text { Descontaminação }\end{array}$} & 3 minutos & 45 & 73,8 & \multirow{6}{*}{$<0,0001$} \\
\hline & 10 minutos & 7 & 11,5 & \\
\hline & 30 minutos & 4 & 6,6 & \\
\hline & 60 minutos & 2 & 3,3 & \\
\hline & Outros: 20 minutos & 2 & 3,3 & \\
\hline & Não soube informar & 1 & 1,6 & \\
\hline \multirow{9}{*}{$\begin{array}{l}\text { Tipos de Materiais e } \\
\text { instrumentais } \\
\text { limpos/descontaminados }\end{array}$} & Espátula de inox & 61 & 100,0 & \multirow{9}{*}{$<0,0001$} \\
\hline & Alicate & 60 & 98,4 & \\
\hline & Palito de inox & 44 & 72,1 & \\
\hline & Lixas & 1 & 1,6 & \\
\hline & Polidores & 3 & 4,9 & \\
\hline & Separador de dedos & 0 & 0,0 & \\
\hline & Cortador de unhas & 8 & 13,1 & \\
\hline & Protetores plásticos para bacias & 0 & 0,0 & \\
\hline & Luvas & 0 & 0,0 & \\
\hline
\end{tabular}

Tabela 2 - Frequências das categorias de variáveis relacionadas ao processo de trabalho. Abril a junho de 2016. Cascavel-PR, Brasil.

\begin{tabular}{lllll}
\hline \multicolumn{1}{c}{$\begin{array}{l}\text { Variável } \\
\text { Utilização de método de }\end{array}$} & Sim Categorias & $n$ & \multicolumn{1}{c}{$\%$} & p-valor \\
esterilização & Não & 57 & 93,4 & $<0,0001$ \\
Método empregado para & Estufa & 4 & 6,6 & \\
esterilização dos materiais e & Autoclave a vapor & 49 & 86,0 & \\
instrumentais & Oxido de Etileno & 7 & 12,3 & $<0,0001$ \\
& Outros: Panela de pressão & 0 & 0,0 & \\
& & 1 & 1,8 & \\
& Espátula de inox & 57 & 100,0 & \\
Tipos de materiais e & Alicate & 57 & 100,0 & \\
instrumentais que são & Palito de inox & 44 & 77,2 & \\
esterilizados & Cortador de unhas & 7 & 12,3 & \\
& Lixas & 0 & 0,0001 \\
& Polidores & 0 & 0,0 & \\
& Separador de dedos & 0 & 0,0 & \\
& Protetores plásticos para bacias & 0 & 0,0 &
\end{tabular}


Temperatura/tempo de exposição dos materiais $200^{\circ} \mathrm{C}$ por 2 horas

$121^{\circ} \mathrm{C}$ por 30 minutos

$132^{\circ} \mathrm{C}$ por 15 minutos

$132^{\circ} \mathrm{C}$ por 4 minutos

Em torno de 7 horas

Outros

Não soube informar

$\begin{array}{lll}4 & 7,0 & \\ 3 & 5,3 & \\ 1 & 1,8 & \\ 0 & 0,0 & <0,0001 \\ 0 & 0,0 & \\ 38 & 64,9 & \\ 11 & 19,3 & \end{array}$

Após a esterilização, 26 (45,6\%) participantes mantêm o material dentro do equipamento de esterilização ou dentro de um recipiente com tampa 16 (28,1\%). Nenhum dos salões de beleza utiliza método de controle do processo de esterilização, ou seja, integradores químicos e indicadores biológicos (Tabela 3).

Tabela 3 - Frequências das categorias de variáveis relacionadas ao processo de trabalho. Abril a junho de 2016. Cascavel-PR, Brasil.

\begin{tabular}{|c|c|c|c|c|}
\hline \multirow{8}{*}{$\begin{array}{l}\text { Periodicidade da desinfecção } \\
\text { ou esterilização dos materiais } \\
\text { (dia-a-dia de trabalho) }\end{array}$} & Categorias & $n$ & $\%$ & p-valor \\
\hline & Entre um atendimento e outro & 17 & 29,8 & \multirow{7}{*}{$<0,0001$} \\
\hline & $\begin{array}{l}\text { Faz uso mais de uma vez do mesmo } \\
\text { material e instrumental para depois }\end{array}$ & 0 & 00 & \\
\hline & realizar a descontaminacão/esterilizacão & & & \\
\hline & Ao final do expediente & 32 & 56,1 & \\
\hline & Uma vez por semana & 1 & 1,8 & \\
\hline & Outros: Usa todos os Kits primeiro & 6 & 10,5 & \\
\hline & Todos os dias pela manhã & 1 & 1,8 & \\
\hline \multirow{2}{*}{$\begin{array}{l}\text { Uso de embalagem para } \\
\text { esterilização dos materiais }\end{array}$} & Sim & 43 & 75,4 & \multirow{2}{*}{$<0,0001$} \\
\hline & Não & 14 & 24,5 & \\
\hline \multirow{4}{*}{$\begin{array}{l}\text { Tipos de embalagem usadas } \\
\text { para esterilização dos } \\
\text { materiais }\end{array}$} & Papel embrulho & 0 & 0,0 & \multirow{4}{*}{$<0,0001$} \\
\hline & Papel filme (plástico) & 0 & 0,0 & \\
\hline & Papel grau cirúrgico & 7 & 16,3 & \\
\hline & Papel alumínio & 36 & 83,7 & \\
\hline \multirow{8}{*}{$\begin{array}{l}\text { Local de armazenamento dos } \\
\text { materiais após os processos de } \\
\text { Reprocessamento }\end{array}$} & Dentro do equipamento de esterilização & 26 & 45,6 & \multirow{8}{*}{$<0,0001$} \\
\hline & Dentro do recipiente sem tampa & 2 & 3,5 & \\
\hline & Dentro de um recipiente com tampa & 16 & 28,1 & \\
\hline & Na gaveta do carrinho de trabalho & 9 & 15,8 & \\
\hline & Em cima do carrinho de trabalho & 1 & 1,8 & \\
\hline & Outros: Junto aos esmaltes & 1 & 1,8 & \\
\hline & Em uma gaveta & 1 & 1,8 & \\
\hline & Mala de manicure/pedicure & 1 & 1,8 & \\
\hline $\begin{array}{l}\text { Uso de método de controle do } \\
\text { processo de esterilização }\end{array}$ & Não & 61 & 100,0 & - \\
\hline
\end{tabular}

\section{DISCUSSÃO}

A limpeza e lavagem dos instrumentos perfurocortantes, é de suma importância para a eficácia das demais etapas, pois nesta, ocorre à retirada de sujidades diminuindo 
a quantidade de micro-organismos existentes, e deve ser feita com detergentes enzimáticos, ação mecânica com uso de escovas e de EPIs apropriados ${ }^{15}$.

A descontaminação é um processo que retira parte da sujidade (sangue, secreções, exsudatos e outros fluidos) de artigos, diminuindo-se assim, a carga microbiana e melhorando a efetividade da limpeza. Caso os artigos contenham resíduos de matéria orgânica, há a possibilidade de o agente desinfetante ou esterilizante não atingir os micro-organismos de forma a eliminá-los. No processo de descontaminação é recomendado o uso do detergente enzimático, que tem como vantagens a remoção de matéria orgânica, baixa toxicidade e não ser corrosivo ao instrumental ${ }^{16,17}$.

Em relação ao álcool, este é utilizado na limpeza de artigos não críticos, ou seja, aqueles os quais os procedimentos por eles utilizados tiveram pouquíssimo risco de desenvolvimento de infecções ou que entraram em contato com a pele íntegra. Requer limpeza ou desinfecção de baixo nível e/ou intermediária, dependendo do risco de transmissão secundária de micro-organismos de importância epidemiológica. 0 álcool não deve ser utilizado como agente desinfetante, mas, como um complemento do processo de desinfecção ${ }^{18}$.

Após a lavagem, os instrumentos devem ser enxaguados, secos e acondicionados em embalagens apropriadas para o processo de esterilização que será adotado. Nesta embalagem, deverá constar a data de esterilização e o nome da pessoa que foi responsável por tal procedimento. Esta embalagem é válida por sete dias e deve ser aberta na frente do cliente, ${ }^{19}$ caso não seja utilizada neste período, deve sofrer novo processo de esterilização.

$\mathrm{Na}$ tabela 2, a maioria dos entrevistados faz uso da estufa como principal método de esterilização. Entre os que afirmaram não utilizar instrumentos esterilizados ou não possuírem equipamentos para realizar tal prática, a justificativa foi o fato de que cada cliente leva os seus próprios materiais.

0 método de esterilização por estufa é amplamente utilizado entre manicures e pedicures. Além disso, é bastante divulgado o uso de "forninhos", e não estufas do tipo forno de Pasteur, que não permitem o uso de termômetro externo. Outro problema é a prática habitual de abrir o equipamento antes do término do processo de esterilização ${ }^{20}$.

A estufa (forno de Pasteur) possui restrições quanto ao uso no que se refere ao tempo de pré-aquecimento, exposição do material ao processo e, cuidados especiais na sua retirada. A não observância destes aspectos pode provocar choques térmicos com 
possivel recontaminação do material submetido à esterilização, por não constituir um método recomendado ou aprovado para esterilização pela ineficácia na destruição de micro-organismos ${ }^{4}$.

Outro agravante da estufa é o fato de não possuir termostato e nem local para aferir a temperatura com termômetro, tornando-se inadequada para a esterilização dos materiais, visto que, não se tem uma comprovação que a mesma atingiu tal temperatura em determinado tempo estipulado, eliminando assim, os micro-organismos ${ }^{12}$.

A partir da publicação da RDC n 15 de 2012 e da Resolução SESA n 700/2013 do Paraná, ficou estritamente proibida à utilização de estufas para a esterilização de produtos para saúde, além de fornos elétricos, panelas de pressão e equipamentos à base de radiação ultravioleta ${ }^{13,14}$.

Ressalta-se que apesar de a estufa ser utilizada com maior frequência pelos salões de beleza incluídos na pesquisa, os parâmetros de temperatura e tempo de exposição dos materiais são variados e não padronizados em 38 (64,9\%) locais, discrepantes em relação à literatura. 0 uso da panela de pressão também foi citado durante a pesquisa por um estabelecimento $(1,8 \%)$.

Estes resultados são semelhantes a outros estudos que envolveram o tempo e a temperatura de exposição de materiais indicados para esterilização em estufa e autoclave, os quais foram muito além do que é preconizada ${ }^{4}$. Em estudo realizado no estado de São Paulo, das manicures entrevistadas, nenhuma soube informar a diferença entre autoclave e estufa ${ }^{21}$.

A ausência de uma padronização na realização do processo de esterilização prejudica e interfere na eficácia e no uso destes materiais. Para que o processo de esterilização seja totalmente efetivo, a temperatura e o tempo são imprescindíveis e devem ser rigorosamente respeitados, levando-se em consideração que o termo "esterilização" se refere ao processo que elimina todas as formas microbianas de vida ${ }^{22}$. Sendo assim, de um modo geral, esse processo pode ser realizado através de métodos físicos, químicos e físico-químicos ${ }^{23}$.

O Ministério da Saúde determina que em caso da utilização da estufa, seja utilizada a temperatura de $160^{\circ} \mathrm{C}$ durante um período de 2 horas ou $170^{\circ} \mathrm{C}$ por 1 hora. Já em casos de utilização de autoclaves, a temperatura pode variar de $121^{\circ} \mathrm{C}$ a $134^{\circ} \mathrm{C}$, com tempo de 30 minutos ou 15 minutos, respectivamente a depender das recomendações estabelecidas pelo fabricante ${ }^{22}$. 
Sabe-se que para que o processo de esterilização seja efetivo é necessário que os fatores tempo e temperatura sejam rigorosamente obedecidos. Na estufa, a esterilização é promovida através da propagação do calor seco de forma lenta e desigual, fazendo com que ocorra a oxidação dos micro-organismos ${ }^{24}$.

A autoclave como método de escolha do processo de esterilização foi citada por sete $(12,30 \%)$ das entrevistadas, equipamento este no qual a esterilização se dá através do vapor saturado sob pressão, onde a combinação do tempo, temperatura e pressão faz com que ocorra a desnaturação das proteínas dos micro-organismos, levando-os a morte ${ }^{24}$.

Recomenda-se que a temperatura/tempo/pressão adotada seja a estabelecida pelo fabricante. Assim, a utilização de autoclaves automáticas deve ser preferida pelo fato de minimizarem as possibilidades de interferência no processo de esterilização 4 .

Os achados permitem inferir que muitos profissionais não seguem as recomendações relacionadas à esterilização, não sabem informar quanto tempo os materiais permanecem no equipamento utilizado e qual a temperatura correta para que os mesmos sejam esterilizados. A falta de termostato nos equipamentos é outro fator agravante para o monitoramento do processo de esterilização, pois a mensuração da temperatura é indispensável para a eliminação de todas as formas de vida microbiana.

Da mesma forma, o uso inadequado de equipamentos pode ser favorecido pela falta de conhecimento dessas profissionais quanto aos métodos de esterilização existentes e padronizados no Brasil, mas não somente este ${ }^{21}$. Segundo as participantes a não utilização pode estar relacionado ao maior custo do equipamento comparado às estufas, a manutenção do equipamento, aos tipos de invólucros utilizados para acondicionamento dos materiais e à falta de conhecimento sobre o uso correto do equipamento e o processo que a mesma realiza.

No estudo, pode-se perceber que um número expressivo de manicures/pedicures acreditavam que o método de esterilização em panela de pressão ou uso de álcool culminava na eliminação de todos os micro-organismos.

A utilização do papel alumínio foi justificada pelas participantes da pesquisa devido ao fato de os materiais, como os alicates não perderem o "fio" com sua utilização, não sendo o indicado pelas legislações vigentes no país.

O objetivo da embalagem para envolver o material é, além de permitir a penetração do agente esterilizante, assegurar sua esterilidade, preservando-o diante das 
condições de transporte e armazenamento, favorecendo a sua transferência estéril até seu uso. Diversos são os tipos de embalagens disponíveis no mercado que podem ser adotadas pelas instituições de saúde/beleza e que são compatíveis com os métodos de esterilização empregados ${ }^{25}$.

O papel grau cirúrgico é uma embalagem descartável, geralmente formada por um lado de papel e um lado de filme plástico, sendo disponível comercialmente em vários formatos, como por exemplo, tubos e envelopes. Este tipo de embalagem exige selagem térmica e esterilização ${ }^{26}$. É indicado para materiais leves, frágeis e pouco resistentes à tração, possibilita a visualização dos materiais na apresentação, pois possui uma face de filme plástico transparente, o que se torna uma vantagem. Deve possuir indicadores químicos impressos na embalagem, mostrando o método de esterilização a que são compatíveis ${ }^{27}$.

Realizada a esterilização, os materiais esterilizados devem ser estocados em recipientes com tampas ou prateleiras, para que as embalagens estejam acondicionadas de forma organizada e em espaços adequados; o material das prateleiras deve ser lavável, em aço inox ou material plástico; as prateleiras ou armários devem estar a no mínimo $20 \mathrm{~cm}$ do piso, $5 \mathrm{~cm}$ das paredes e $45 \mathrm{~cm}$ do teto, preferencialmente fechados; o local ter acesso restrito; ter iluminação artificial ou natural indireta, para não interferir no esfriamento ou aquecimento do ambiente; temperatura ambiente controlada entre $18^{\circ} \mathrm{C}$ e $24^{\circ} \mathrm{C}$; e, umidade relativa do ar de $40 \%$ a $60 \%{ }^{27}$.

Com relação ao método adotado para a validação do processo de esterilização, 61 (100\%), dos entrevistados declararam não fazer nenhum tipo de teste, seja biológico, químico ou físico, para identificar se os materiais foram processados de maneira correta e em conformidade com os parâmetros exigidos.

Os processos de esterilização devem ser diariamente monitorados através de uma combinação de indicadores químicos, biológicos e controles físicos, que avaliam as condições de esterilização e eficácia do ciclo de esterilização ${ }^{27}$.

Dentre os indicadores que podem ser utilizados para monitoramento do processo de esterilização, destacam-se ${ }^{26}$ :

a) Integradores químicos: os quais podem ser divididos em seis classes, sendo a mais conhecida a fita zebrada que deve ser fixada em todos os invólucros e examinado após a esterilização e antes do invólucro ser aberto para uso; 
b) Indicadores de parâmetro único e multiparamétricos: também chamados de indicadores de parâmetro único, designados para reagir com um parâmetro específico do ciclo de esterilização, por exemplo, a temperatura, no caso da autoclave. Na prática, geralmente são usados para avaliar a temperatura mínima alcançada no centro geométrico de grandes pacotes ou de caixas cirúrgicas volumosas. Já os indicadores multiparamétricos, são designados para reagir com dois ou mais parâmetros críticos do ciclo de esterilização;

c) Indicadores biológicos: são preparações padronizadas de esporos bacterianos, comprovadamente resistentes ao método que se propõe monitorar, contendo em torno de $10^{6}$ Unidades Formadoras de Colônias (UFC) por unidade de papel filtro. Os esporos são utilizados como indicadores biológicos na avaliação do sucesso da esterilização por serem altamente resistentes às condições ambientais adversas.

Assim, ressalta-se a importância da implementação de boas práticas em saúde, visando tanto a biossegurança dos profissionais de saúde, quanto dos clientes que são atendidos nestes estabelecimentos que prestam serviços de embelezamento.

\section{CONCLUSÃO}

A realização desta pesquisa permitiu verificar que $86,0 \%$ dos entrevistados não seguem as normas da resolução estadual, pois utilizam a estufa como principal método de esterilização, $64,9 \%$ utilizam tempos de exposição dos materiais e temperaturas do equipamento não recomendadas pelas legislações vigentes, $83,7 \%$ utilizam como invólucro o papel alumínio e toda totalidade não utilizam métodos de controle e eficácia dos processos de esterilização.

Em relação às recomendações de biossegurança, observou-se baixa adesão e pouco conhecimento, devido ao grau de escolaridade e a baixa capacitação dos profissionais evidenciadas por insuficiente quantidade de instrumentais, inadequada realização do reprocessamento de instrumentais potencialmente contaminados, uso incorreto de soluções químicas desinfetantes, não utilização de EPI adequados ou de forma incorreta e, falhas na prevenção de acidentes, que podem ser evitados pelo ato de manter as condições físicas e sanitárias satisfatórias, de acordo com as normas vigentes. 
A criação de grupos de estudos direcionados aos profissionais do ramo de beleza de modo geral, com discussões de temas relevantes visando à implementação de medidas de biossegurança e de boas práticas, auxiliaria no aperfeiçoamento destes profissionais e nas dúvidas que ocorrem no cotidiano desta atividade que cresce sobremaneira no país e no mundo.

Como limitação da pesquisa, destaca-se o aspecto de não ter sido realizada em todos os salões de beleza da localidade, o que poderia revelar outros perfis. Assim, novos estudos dessa natureza devem ser realizados, a fim de dar maior visibilidade ao processo de trabalho dos profissionais desse setor, em especial em relação a biossegurança.

\section{REFERÊNCIAS}

1. Ataei BK, Shirani SMA, Ataie M. Evaluation of Knowledge and Practice of Hairdressers in Women's Beauty Salons in Isfahan about Hepatitis B, Hepatitis C, and AIDS in 2010 and 2011. Hepat seg. 2013; 13 (3):e6215.

2. Garbaccio JL, Oliveira AC. Adesão e conhecimento sobre o uso de equipamentos de proteção individual entre manicures e pedicures. Rev Bras Enferm. 2015; 68(1):52-9.

3. Garbaccio JL, Oliveira AC. O risco oculto no segmento de estética e beleza: uma avaliação do conhecimento dos profissionais e das práticas de biossegurança nos salões de beleza. Texto \& Contexto Enferm. 2013; 22(4):989-98.

4. Pimenta GRP, Jesus LO, Almeida CS, Souza FO, Barbosa NS. Ações de promoção e prevenção à saúde do trabalhador sob risco de exposição e transmissão de hepatites virais. Rev APS. 2017; 20(1):140-4.

5. Nam DP, Anil S. The Value of Cosmetology Licensing to the Health, Safety, and Economy of America. Washington: NDP analytics; 2015.

6. Walsh SA. Beyond the Polish: An Examination of Hazardous Conditions in Nail Salons and Potential Solutions for the Industry in New York City. J Law Policy. 2012; 21(1):243-82.

7. Shendell DG, Mapou AEM, Kelly SW, Lewis AG, Houlroyd JL, Murtha AT. Assessing safety and health knowledge and awareness of young cosmetology students using a Salon Safety Quis. J chem health saf. 2013; 20(6):12-8. 
8. Al-Rabeei NA, Al-Thaifani AA, Dallak AM. Knowledge, Attitudes and Practices of Barbers Regarding Hepatitis B and C Viral Infection in Sana's City, Yemen. J community health. 2012; 37(5):935-9.

9. Barbosa LD, Sasso RN, Amadei JL. Manicure/pedicure technicians: Biosecurity knowledge and practices for viral hepatites. Rev Bras Promoç Saúde. 2015; 28(3):3619.

10. Moreira ACA, Silva FL, Silva JKF, et al. Grau de informações dos profissionais de salões de beleza sobre AIDS e hepatite. Rev Ciênc Méd Biol. 2013; 12(3):359-66.

11. Yoshida CH, Oliveira RA, Coelho PG, Fonseca FLA, Filipini R. Processo de Esterilização de instrumentais em estabelecimentos comerciais com serviços de manicures e pedicuros. Acta Paul Enferm. 2014; 27(1):18-22.

12. Diniz AF, Matté GR. Procedimentos de biossegurança adotados por profissionais de serviços de embelezamento. Saúde Soc. 2013; 22(3):751-9.

13. Ministério da Saúde (BR). Resolução RDC $n^{\circ}$ 15, de 15 de março de 2012. Dispõe sobre requisitos de boas práticas para o processamento de produtos para saúde e dá outras providências. Diário Oficial da República Federativa do Brasil, Brasília (DF) 2012 mar 19; Seção 1:43-46.

14. Paraná. Secretaria de Saúde. Resolução n 700, de 06 de dezembro de 2013. Dispõe sobre as condições para instalação e funcionamento dos Estabelecimentos de Salão de Beleza, Barbearia e/ou Depilação no Estado do Paraná. Secretaria de Estado da Saúde, 2013. Diário Oficial do Estado do Paraná, Curitiba (PR); 2013.

15. Alexsandra AA, Derek GS, Amy GL, Kelly SW, Murtha AT, Houlroyd JL. The "Salon Safety Quiz" for pre-/post-evaluation assessment when training young cosmetology workers in public secondary schools. J chem health saf. 2015; 22(2):14-22.

16. Ministério da Saúde (BR). Folheto publicitário: Hepatite B e C são doenças silenciosas - veja como deixar as hepatites longes do seu salão de beleza. Brasília: Ministério da Saúde; 2011.

17. Prince A, Stephen KB, Hope A, Somuah D, Dadzie RKE, Odame EA. High prevalence of hepatitis $B$ and poor knowledge on hepatitis $B$ and $C$ viral infections among barbers: a cross-sectional study of the Obuasi municipality, Ghana. BMC Public Health. 2015; 15:1041.

18. Ministério da Saúde (BR). Agência Nacional de Vigilância Sanitária (ANVISA). Resolução RDC $n^{\circ}$ 50, de 21 de fevereiro de 2002. Dispõe sobre o Regulamento Técnico 
para planejamento, programação, elaboração e avaliação de projetos físicos de estabelecimentos assistenciais de saúde. Diário Oficial da República Federativa do Brasil, Brasília (DF); 2002.

19. São Paulo. Secretaria de Saúde. Manual de orientação para instalação e funcionamento de institutos de beleza sem responsabilidade médica. 2012.

20. Yang J, Hall K, Nuriddin A, Woolard D. Risk for hepatitis B and C virus transmission in nail salons and barbershops and state regulatory requirements to prevent such transmission in the United States. J Public Health Manag Pract. 2014; 20(6):E20-E30.

21. Sobrinho HMR, Gomes CM, Ferreira BD, Cunha FN, Moraeset MLDS, Lima RACO, et al. Evaluation of knowledge and biosecurity practices in a sample of the professionals beautification of Goiania-Goias. J Health Sci Inst. 2014; 32(4):343-52.

22. Ministério da Saúde (BR). Agência Nacional de Vigilância Sanitária (ANVISA). Resolução $\mathrm{n}^{\circ}$ 2.606, de 11 de agosto de 2006. Dispõe sobre as diretrizes para elaboração, validação e implantação de protocolos de reprocessamento de produtos médicos e dá outras providências. Diário Oficial da República Federativa do Brasil, Brasília (DF), 2006 agost 14; 1-4.

23. Tavares SSF, Sousa JTS, Tipple AFV, Souza ACS, Pimenta FC, Anders PS. Eficácia da estufa de Pasteur como equipamento esterilizante em consultórios odontológicos. Rev Esc Enferm USP. 2008; 42(1):160-67.

24. Tipple AFV, Pires FV, Guadagnin SVT, Melo DS. O monitoramento de processos físicos de esterilização em hospitais do interior do estado de Goiás. Rev Esc Enferm USP. 2011; 45(3):751-7.

25. Pereira MCO. Preparo, embalagem, transporte e armazenagem. In: Associação Paulista de Epidemiologia e Controle de Infecção Relacionada Assistência à Saúde (APECIH): Limpeza, desinfecção e esterilização de artigos em serviços de saúde. São Paulo: Câmara Brasileira do Livro; 2010.

26. Graziano KU, Silva A, Psaltikidis EM. Enfermagem em centro de material e esterilização. São Paulo: Manole; 2011.

27. Sociedade Brasileira de Enfermeiros de Centro Cirúrgico (SOBECC). Práticas recomendadas. São Paulo: Komedi; 2013. 
Conflito de interesses: Os autores declaram não haver conflito de interesses.

\section{Participação dos autores:}

- Concepção: Bordin V, Alves DCI.

- Desenvolvimento: Bordin V, Alves DCI, Martins LK, Luz MS.

- Redação e revisão: Bordin V, Alves DCI, Martins LK, Luz MS, Matos FGOA.

Como citar este artigo: Bordin V, Alves DCl, Martins LK, Luz MS, Matos FGOA. Reprocessamento de materiais utilizados em salões de beleza e biossegurança dos profissionais envolvidos. Journal Health NPEPS. 2018 juldez; 3(2):441-456. 